\title{
IOT Based Automation System to Prevent Crop Vandalization by Rain Water in Agricultural Regions
}

\author{
Kajal Sainia ${ }^{21}$, Hunny Sainib2, Ankush Kumar Gaur ${ }^{\mathrm{c} 3}$ \\ aDepartment of Computer Science and Engineering, Kanpur Institute of Technology \\ Plot No. A-1, UPSIDC Industrial Area,Rooma, Kanpur-208001 \\ Uttar Pradesh \\ , India \\ 1 kajalsaini032@gmail.com \\ ${ }^{b}$ Department of Electronics and Communication Engineering, Kanpur Institute of Technology \\ Plot No. A-1, UPSIDC Industrial Area,Rooma, Kanpur-208001 \\ Uttar Pradesh \\ , India \\ 2 iplatonic19@gmail.com \\ 'Department of Computer Science and Engineering, Kanpur Institute of Technology \\ Plot No. A-1, UPSIDC Industrial Area,Rooma, Kanpur-208001 \\ Uttar Pradesh \\ , India \\ ${ }^{3}$ ankushkumardddm@gmail.com
}

\begin{abstract}
India's keystone is Agriculture. Around 70 percent of India's revenue comes from Agriculture. Conversely the population of India amplifies each and every day which requires efficient and well planned decision making techniques for the production of crops. In this research paper we find the intensification of the structures which prevent destruction of crops due to uneven and heavy rainfall. The goal is achieved by the concept of Embedded System design using IOT technology. This is done automatically without any human interference. Here we first identifies the water level in the agriculture field during rainfall by using water level sensors, if the water level exceeds there limit that will cause spoilage of crop then the device are automatically cover the agriculture field. It also identifies the temperature of the crops by using temperature sensor during the sunny days, if the heat causes spoilage of crops due to intensive sun rays then the device will automatically covers the agriculture field. After covering the agriculture field it will send the alert message using GSM module to the farmer and simultaneously the water of rain is collected through piles that will be reuse later for irrigation. To achieve this we use microcontroller, Solar panels, GSM module, DC motor, sensors, Switched-mode power supply (SMPS), Rechargeable battery.
\end{abstract}

Keywords: IOT, Sensors, Embedded System, Microcontroller, Solar panels, GSM module, DC motor, SMPS, Rechargeable battery, Agriculture.

\section{Introduction}

Agriculture is the foundation of India. It secures second position in global level in farm yield. Agriculture and other allied activities engaged around 50 percent of the Indian labor force and add 17 to 18 percent to India's Gross domestic product (GDP). In India, usual food utilization at present is 550 gram per capita per day, while in USA and China are 2850 gram and 980 gram, correspondingly $[1,2]$. The total gross irrigated area has in excess of quadrupled from 22.6 million ha in 1950-51 to 99.1 million ha in 2011-2012 [3]. Potential modification in Rainfall, Carbon dioxide concentration and temperature are likely to considerably impact crop intensification [2]. The data recorded according shows the relationship between rainfall and minimum water needed by crops [4]. 


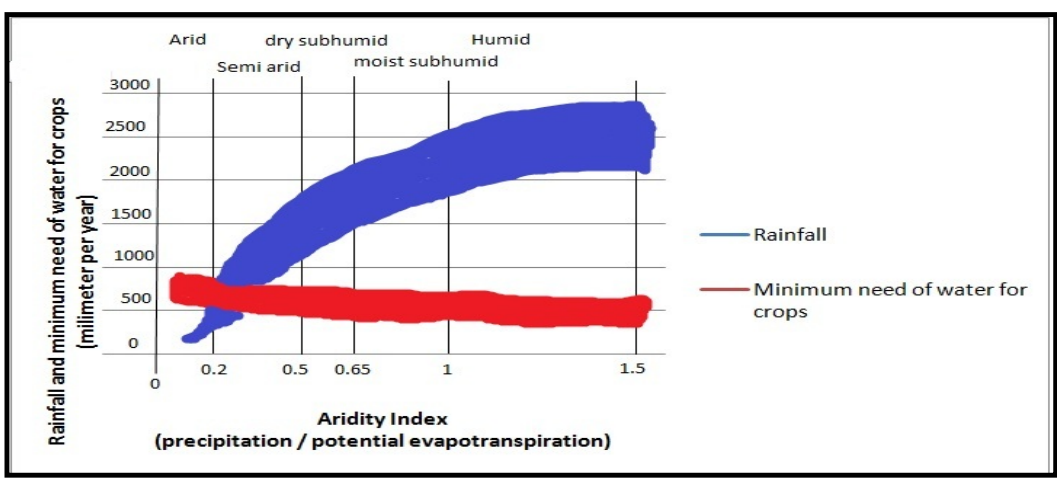

Figure 1.Rainfall and minimum need of water for crops comparison

The objective of this paper is to describe the Embedded System which Prevent Crop Vandalization by Rain Water in Agricultural Regions. Heavy rainfall and excessive sunlight are serious harm to crops, so preventive measures to protect field from such uncontrolled phenomenon are essential for not only protecting crops but also for the livelihood of farmers. Our IOT based embedded system is highly useful in this regards. Embedded system is a collection of a computer processor, computer memory, and I/O peripheral devices which has a committed function inside a superior mechanical or electrical system. Currently there is no proper protection of crops from vandalization by rain water, management of the rain water and protection of crops from access heat. This paper also explain some of the traditional methods that are used by agriculturists like making outlet in the field of crop in order to pass rain water through it but the method is not efficient enough to pass all rain water and hence the spoilage of crop may cause. The embedded system resolves the struggle faced by farmers due to the vandalization of crops due to excess rain water or due to excess heat. Rakhee Patil etc all [5] was proposed a embedded system model in which it uses a raspberry pi board, WIFI module and ARM7 LPC2148.

In this paper, we shows a cost effective system based on real world implementation which is simple to use and has simple equipments for the agriculturist and encompass a capability to defend crop field successfully.

\section{System Architecture}

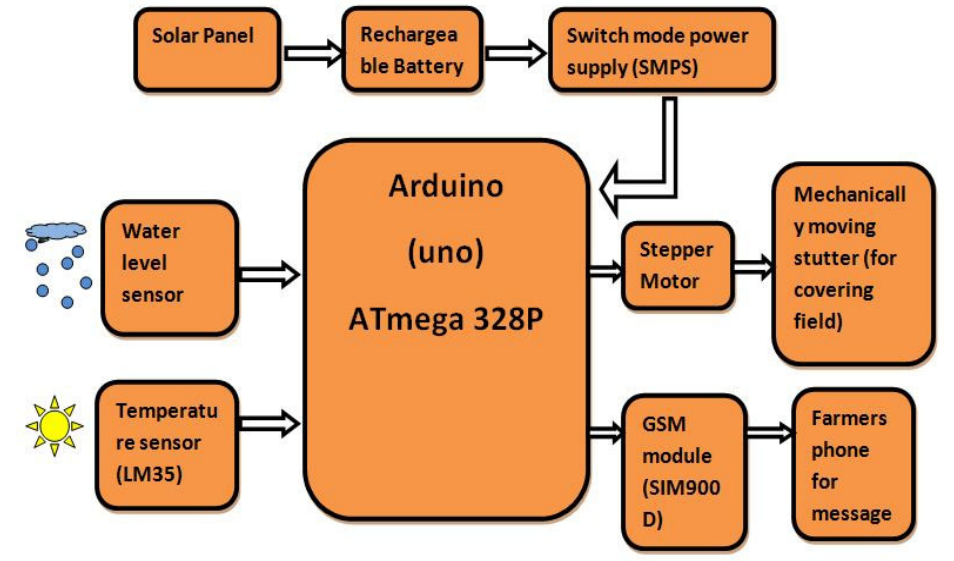

Figure 2. Block Diagram of System

\subsection{Component Explanation}

\subsubsection{Water Level Sensor}


It is the kind of sensors which detect the water level depth and generate signal accordingly.

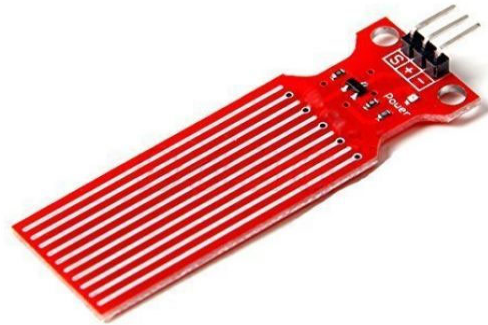

Figure 3. Water Level Sensor

\subsubsection{Temperature Sensor}

It is a sensor that will detect the heat of the material and turns on but some temperature sensor are activated when they are in touch with the material and some uses convection and radiation to check changes in temperature.

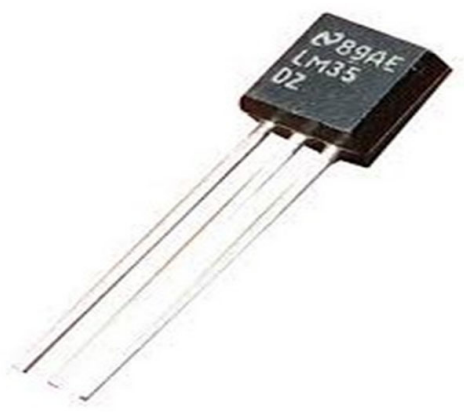

Figure 4. Temperature Sensor

\subsubsection{Arduino Uno}

It is the microcontroller that is totally based upon the MicrochipATMega328P microcontroller. It is the brain of embedded system we use and control the other devices.

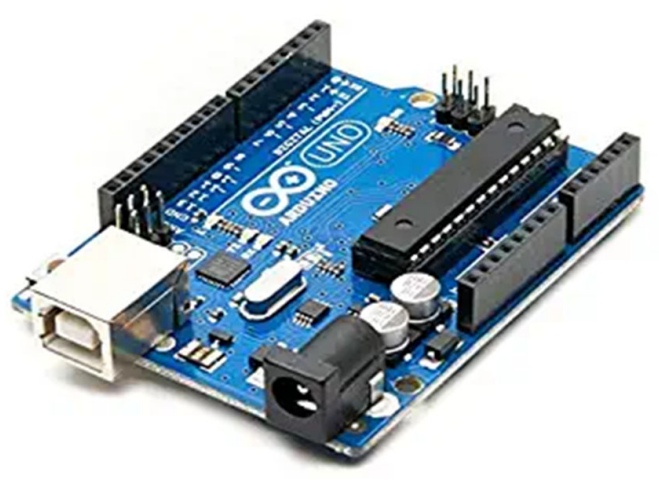

Figure 5. Arduino Uno 


\subsubsection{Stepper Motor}

It is the kind of motor that rotate like normal motors but the difference is stepper motor divide the full rotation into a number of steps. These divisions are done in such a manner that in each rotation equal numbers of steps are present.

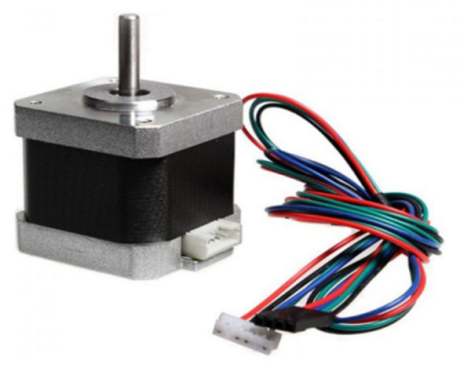

Figure 6. Stepper Motor

\subsubsection{GSM Module}

It is the kind of chip used to create the communication between the device and a GSM module. It is initially used for $2 \mathrm{G}$ and $3 \mathrm{G}$ cellular communication [6].

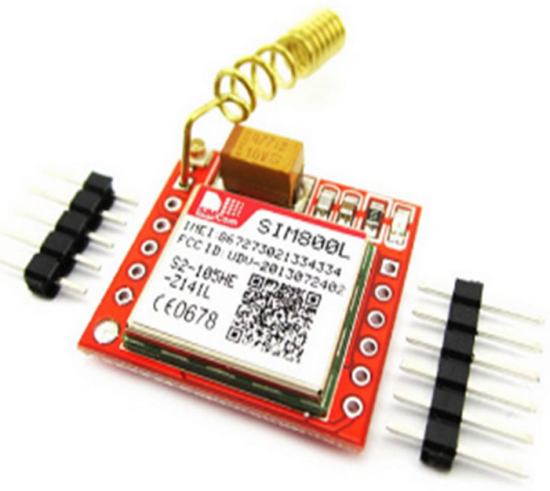

Figure 7. GSM Module

\subsection{Overview}

This IOT based embedded system majorly consist of temperature sensor, water level sensor which collects the stimulus from external environment, based on such stimulus microcontroller ( Arduino uno) decide to execute various functionalities such as automatic covering the field with mechanically operated Tarpaulin shed, to protect the field from heavy rainfall and excessive heat of sunlight. Moreover microcontroller is interfaced with GSM module, to inform the farmer about every action, which the controller is performing on the field shown above in figure 2. 


\section{Flow Chart}

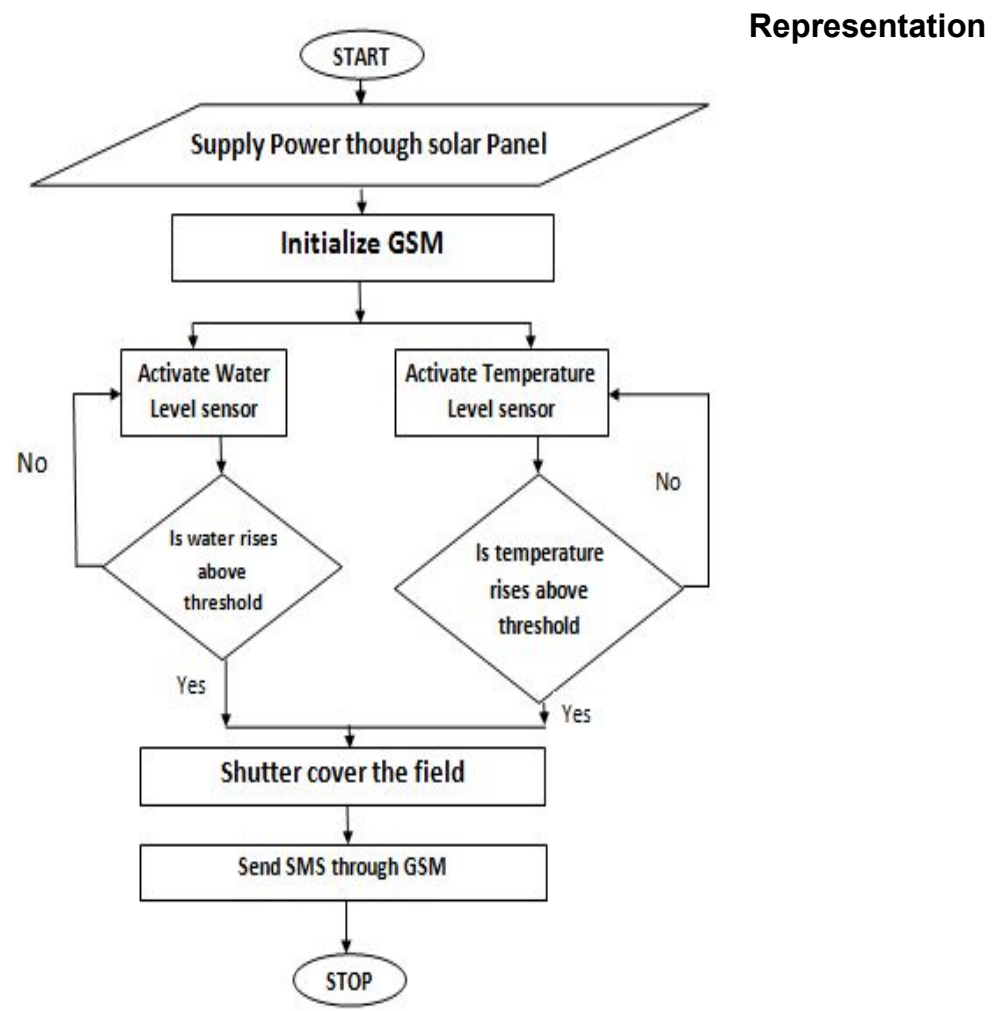

Figure 8. Block Diagram of System

\section{System Model Explanation}

Solar power enabled IOT based system operates at 5 volts DC supply. For this purpose we are installing solar panel to capture solar energy and convert it to get electrical energy which is used to recharge the lithium rechargeable batteries, which along with 5 volts DC convertor provided regulated supply of 5 volts to arduino uno (AT mega 328P microcontroller) and GSM module[9].

Water level sensor were installed in the field to continuously measure the level of water in the field during heavy rainfall and microcontroller continuously analyzing the data obtained from sensor. As soon as the level of water reached above threshold value microcontroller will activate the robotic vehicle comprised of stepper motor mechanism to mechanically operate the Tarpaulin shed which is mount on a specially designed wooden or plastic structure.

The specially designed wooden or plastic structure consists of rubber wires whose tensile strength is good. They are mounting on the strong plastic or wooden base. The structure is designed in such a manner that the two plastic or wooden rods have equal height while third rod has larger height than the other two. The all three rods are placed in one two dimensional plane as shown in figure 9 .

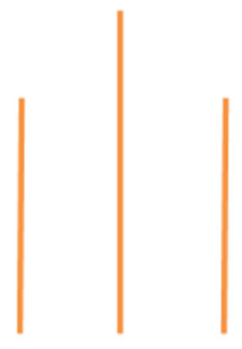


Figure 9. 2D Plane Structure

Similarly the other three rods are placed opposite to the given 2D plane and formed the three dimensional plane structure and then join each of the end corresponding to similar other end as shown in figure 10.

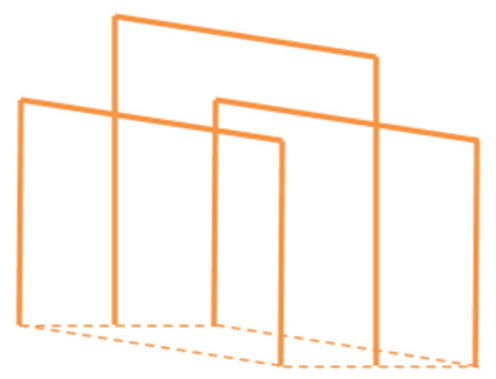

Figure 10. 3D Plane Structure

Now the rubber wires are connected in this structure as shown in the figure 11.

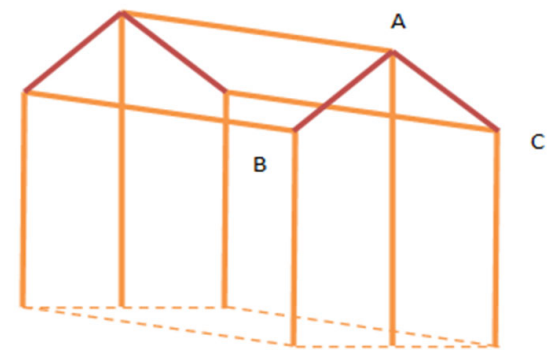

Figure 11. Complete 3D Plane Structure

Now the tarpaulins are installed at the two edges shown by brown color in figure 11. The tarpaulin will be pulled up until it reaches the point $A$ (figure 11) by the stepper motor that will be installed in point $B$ (figure11) and point $C$ (figure 11). The whole system is controlled and operates by the microcontroller automatically according to the extent of rainfall and intensity of the sun rays (temperature).

Now after covering the field with tarpaulin shed, GSM module get activated and inform the farmer about the action taken by microcontroller.

In the similar fashion temperature sensor will also perform its functionality that is as soon as ambient temperature exceeds above predefined threshold (threshold value vary according to the crops), mechanical shutter automatically get operated and microcontroller informs the farmer simultaneously.

\section{Control Circuit}




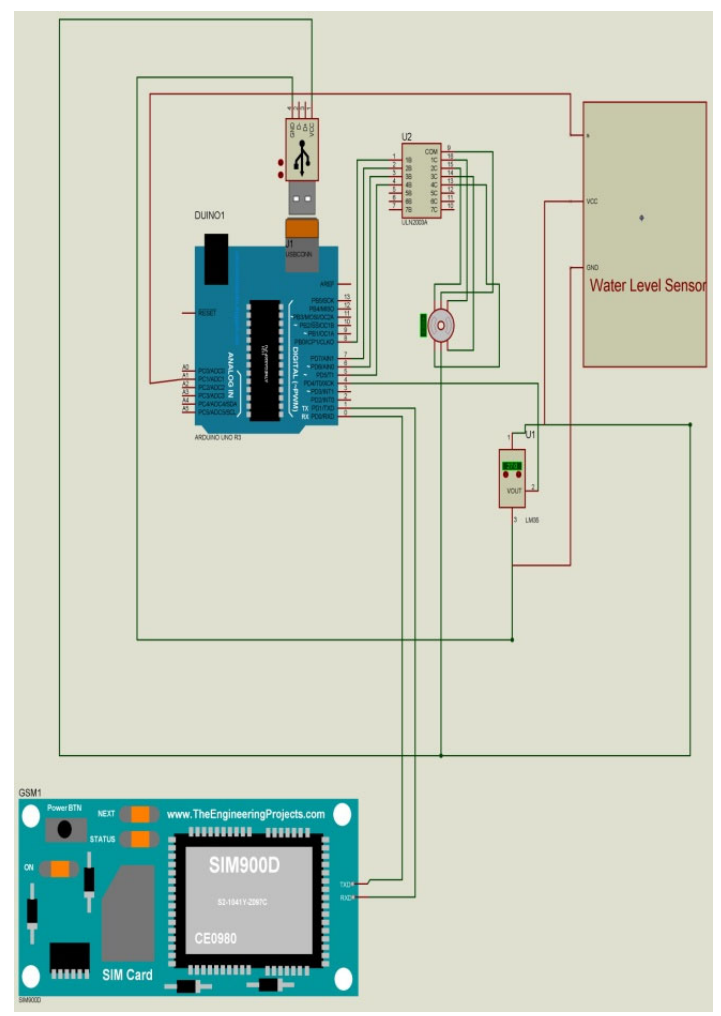

Figure 12. Controller Circuit

The ATMega328P microcontroller [8] is the main controller module unit which is being interfaced with stepper motor, GSM module [7] and is operated with 5V DC Supply which is being generated through solar panel (Solar energy to electrical energy converter circuit)

Digital pin $0(R X D)$ and pin 1(TXP) of the microcontroller are connected to TXD and RXD pins of SIM900D GSM module respectively which is used to send message to the user to inform the user about covering of field.

Analog pin A1 of microcontroller acts as input pin which collects the information about water level in the field through the rain water level sensor as shown in the circuit diagram. Similarly digital pin 4 collects the information about temperature through LM35 temperature sensor.

Based on above received inputs at analog pin A1 and digital pin 4 decision to operate stepper motor which in turn cover the field with tarpaulin sheet installed on an specially designed structure as shown in figure $9,10,11$.

Digital pin 5, 6, 7 and 8 acts as output which is being interfaced with ULN2003A driver integrated circuit, which is used to drive stepper motor precisely as per our requirement.

\section{Conclusion}

As this is the era of "Internet of Things" so utilizing the technology for protecting the crops from involuntary actions of natural phenomenon (like heavy rainfall) will be great relief and extremely helpful for farmers, who are the backbones of our country. Moreover above prescribed system once installed can work for a long period of time because of its highly robust nature. Hence installing such system in the field will reflect a great mark to economy as well and giving fruitful desired results to the farmers. 


\section{References}

[1] RK Mall, A Gupta, R Singh, RS Singh, LS Rathore, " Water resources and climate change: An Indian perspective " Current Science, vol. 90, no. 12, p. 1610-1626, 2006.

[2] RK. Mall, Ranjeet Singh, Akhilesh Gupta, G. Srinivasan, L. S. Rathore, " Impact of Climate Change on Indian Agriculture: A Review" Climatic Change, vol. 78, p. 445-478, 2006.

[3] Rohitashw Kumar, Harender Raj Gautam, " Climate Change and its Impact on Agricultural Productivity in India " Journal of oJ Climatology \& Weather Forecasting, vol. 2, no. 1, p. 1-2, 2006

[4] B. Venkateswarlu, Arun K. Shanker, Dryland Agriculture: Bringing Resilience to Crop Production Under Changing Climate, Edition ed. Venkateswarlu, B., Shanker, A.K., Shanker, C., Maheswari, Casterta: Springer Netherlands, 2012, pp. 56.

[5] Vedashree.S, K. Neeresh kumar, Smitha.M, Thippesh.D.R, Kumuda.B, Zoya parvez, Deepa .B, " Protection of Crops and Proper Usage of Rain Water with Embedded System Using GSM Technology" International Journal of Engineering Science and Computing, vol. 7, no. 6, p. $12682-$ 12684, 2017

[6] Venkat Mattela, "electronicsforu", 1969. [Online]. Available: https://www.electronicsforu.com/resources/gsm-module. [30 jan 2019]

[7] Syed Zain Nasir, "The Engineering Projects", 2009. [Online]. Available: https://www.theengineeringprojects.com/. [1 feb 2019]

[8] Tiago, "microcontrolandos", $2012 . \quad$ [Online], Available: https://www.microcontrolandos.blogspot.com.[ 1 feb 2019]

[9] Siddhanta Borah, Ankush Kumar Gaur, Dr. J. Arul Valan, "Sensor Based Alarm System for Preventing Crop Vandalization by Birds in Agricultural Regions" in ICACCT-2019: First International Conference (Springer) on Advanced Communication \& Computational Technology, NIT Kurukshetra, 2019. 